\title{
Optimization of surface roughness in CNC end milling using response surface methodology and genetic algorithm
}

\author{
B. Sidda Reddy ${ }^{1, *}$, J. Suresh Kumar ${ }^{2}$ and K. Vijaya Kumar Reddy ${ }^{3}$ \\ ${ }^{I}$ R.G.M. College of Engineering \& Technology, Nandyal, A.P, INDIA \\ ${ }^{2,3,}$ J.N.T.U.H. College of Engineering, Kukatpally, Hyderabad, A.P, INDIA \\ "Corresponding Author: e-mail: sidhareddy548@gmail.com,Tel+91-9440844600
}

\begin{abstract}
Pre-hardened steel (P20) is a widely used material in the production of moulds/dies due to less wear resistance and used for large components. In this study, minimization of surface roughness has been investigated by integrating design of experiment method, Response surface methodology (RSM) and genetic algorithm. To achieve the minimum surface roughness optimal conditions are determined. The experiments were conducted using Taguchi's $\mathrm{L}_{50}$ orthogonal array in the design of experiments (DOE) by considering the machining parameters such as Nose radius (R), Cutting speed (V), feed (f), axial depth of cut (d) and radial depth of cut(rd). A predictive response surface model for surface roughness is developed using RSM. The response surface (RS) model is interfaced with the genetic algorithm (GA) to find the optimum machining parameter values.
\end{abstract}

Keywords: Pre-hardened steel, DOE, Orthogonal array, RSM, GA.

DOI: http://dx.doi.org/10.4314/ijest.v3i8.8

\section{Introduction}

End milling is the widely used operation for metal removal in a variety of manufacturing industries including the automobile and aerospace sector where quality is an important factor in the production of slots, pockets and moulds/dies (Mike et al, 1999; John and Joseph, 2001). The quality of surface is of great importance in the functional behavior of the milled components. The widely used index of product quality in finish machining process is surface roughness. The factors affecting the surface roughness are the machining conditions work piece material and tool geometry. Therefore in order to obtain better surface finish of a milled product, the optimal machining parameters and tool geometry are to be selected. In the past, Suresh et al (2002) developed a response surface model for surface roughness in terms of speed, feed, depth of cut and nose radius and optimized using genetic algorithm. Oktem et al (2005) used the mathematical model for $\mathrm{R}_{\mathrm{a}}$ in terms of cutting parameters (feed, cutting speed, axial depth of cut, radial depth of cut and machining tolerance). Optimum cutting condition is obtained using GA and the same is verified with experimental measurements. Kadirgama et al $(2008,2010)$ adopted Ant Colony optimization, response surface method and radian basis function network and to optimize the surface roughness in end milling on mould aluminium alloys (AA6061-T6). They found that feed rate is the most significant design variable in determining surface roughness as compared to cutting speed, axial depth, and radial depth.

Gopalswamy et al (2009) used Taguchi method in determining the optimal process parameters in hard machining of hardened steel. They observed that the Cutting speed is the most influencing parameter on tool life and surface roughness. Abbas Fadhel Ibraheem et al (2008) investigated the effect of cutting speed, feed, axial and radial depth of cut on cutting force in machining of modified AISI P20 tool steel in end milling process. They concluded that, higher the feed rates, larger the cutting forces. They also developed the genetic network model to predict the cutting forces. Abou-El-Hossein et al. (2007) predicted the cutting forces in an end milling operation of modified AISI P20 tool steel using the response surface methodology. Rahman et al (2001, 2002) compared the machinability of the P20 mould steel (357 HB) in dry and wet milling conditions. They considered a range of 75$125 \mathrm{~m} / \mathrm{min}$ for the cutting speed and a feed ranging between 0.3 and $0.7 \mathrm{~mm} /$ tooth: they found the cutting forces in both processes 
to be similar, but with the flank wear acceleration higher in dry milling. Furthermore, they observed a better surface finish with wet milling.

Liao and Lin (2007) studied the milling process of P20 steel with MQL lubrication. The cutting speeds were from 200-500 $/ \mathrm{min}$ and the feed between $0.1-0.2 \mathrm{~mm} /$ tooth. The authors found that the tool life is higher with MQL, due to an oxide layer formed on the tool inserts that helped to lengthen the tool life. Saurav Datta et al (2010) optimized the CNC end milling process parameters for surface finish and material removal rate using PCA based Taguchi method. Muammer Nalbant et al (2007) used the multiple regression analysis and artificial neural network models for predicting the surface roughness in turning of AISI 1030 steel material. These techniques used full factorial design and analysis of variance (ANOVA). According to them, Surface roughness increases with increase of feed rate but decreases with increase of insert nose radius. Ekanayake and Mathew (2007) investigated the effect of cutting speed, feed and depth of cut on cutting forces with different inserts while milling AISI1020 steel. According to them, the tool offsets and run-outs affect significantly on the cutting forces when it comes to high speed milling, where small cut sections are employed. This can cause uneven wear of the tool tips due to uneven chip loads. Lajis et al (2008) developed the response surface model to predict the tool life in end milling of hardened steel AISI D2. This technique used central composite design in the design of experiments and ANOVA. The objective was to obtain the contribution percentages of the cutting parameters (cutting speed, feed and depth of cut) on the tool life.

Richard Dewes et al (2003) carried out the study on rapid machining of hardened AISI H13 and D2 moulds, dies and press tools. The primary objective was to assess the drilling and tapping of AISI D2 and H13 with carbide cutting tools, in terms of tool life, workpiece quality, productivity and costs. The secondary aim was to assess the performance of a number of water-based dielectric fluids, intended primarily for EDM operations, against a standard soluble oil cutting fluid, in order to assess the feasibility of a duplex machining arrangement involving HSM and EDM on one machine tool. Mohammad Reza Soleymani Yazdi and Saeed Zare Chavoshi (2010) studied the effect of cutting parameters and cutting forces on rough and finish surface operation and material removal rate (MRR) of AL6061 in CNC face milling operation. The objective was to develop the multiple regression analysis and artificial neural network models for predicting the surface roughness and material removal rate. According to them, in rough operation, the feed rate and depth of cut are the most significant effect parameters on $R_{a}$ and MRR and increases with the increase of the cutting forces.

In this study a predictive model for surface roughness of P20 mould steel in terms of nose radius, cutting speed, feed, axial-depth of cut, and radial depth of cut is then created using RSM. An RS model is coupled with GA to find the optimum process parameter values.

\section{Materials and methods}

The workpiece material used for the present investigation is P20 mould steel of flat work pieces of $100 \mathrm{~mm} \times 100 \mathrm{~mm} \times 10 \mathrm{~mm}$ and the density of the material in metric units is $7.8 \mathrm{~g} / \mathrm{cc}$. The chemical composition of the workpiece material is given in the Table 1.

Table 1: Chemical composition of P20 mould steel

\begin{tabular}{|l|l|}
\hline Composition & Weight (\%) \\
\hline Carbon & $0.35-0.45$ \\
\hline Silicon & $0.2-0.4$ \\
\hline Manganese & $1.3-1.6$ \\
\hline Chromium & $1.8-2.1$ \\
\hline molybdenum & $0.15-0.25$ \\
\hline
\end{tabular}

\subsection{RS model formulation}

The response surface methodology is a widely adopted tool for the quality engineering field. The Response surface methodology (Montgomery, 1984) is a collection of mathematical and statistical techniques that are useful for modeling, analysis and optimizing the process in which response of interest is influenced by several variables and the objective is to optimize this response. Response Surface Methodology uses quantitative data from appropriate experiments to determine and simultaneously solve multi-variable equation. The response surface methodology comprises regression surface fitting to obtain approximate responses, design of experiments to obtain minimum variances of the responses and optimizations using the approximated responses.

In statistical modeling to develop an appropriate approximating model between the response ' $\mathrm{Y}$ ' and independent variables $\left\{\mathrm{x}_{1}\right.$, $\left.\mathrm{x}_{2},------\mathrm{x}_{\mathrm{n}}\right\}$ in general, the relationship is written in the form of

$Y=f\left(\mathrm{x}_{1}, \mathrm{x}_{2},------\mathrm{x}_{\mathrm{n}}\right)+\varepsilon$

where the form of the true response function $\mathrm{Y}$ is unknown and perhaps very complicated, and $\varepsilon$ is a term that represents other sources of variability not accomplished for in Y. usually $\varepsilon$ includes effects such as measurement error on response, back ground noise, the effect of the other variables and so on. Usually $\varepsilon$ is treated as statistical error, often assuming it to have a normal distribution with mean zero and variance $\sigma^{2}$. 
$E(y)=\hat{Y}=E\left[f\left(\mathrm{x}_{1}, \mathrm{x}_{2}, \ldots, \mathrm{x}_{\mathrm{n}}\right)\right]+E(\varepsilon)=f\left(\mathrm{x}_{1}, \mathrm{x}_{2}, \ldots, \mathrm{x}_{\mathrm{n}}\right) ;$

The variables $\mathrm{x}_{1}, \mathrm{x}_{2}, \ldots, \mathrm{x}_{\mathrm{n}} \mathrm{Eq}$.(2) are usually called the natural variables, because they are expressed in the natural units of measurements such as degrees, Celsius, pounds/square inch etc. in much RSM work it is convenient to transform the natural variables to coded variables $\mathrm{x}_{1}, \mathrm{x}_{2}, \ldots, \mathrm{x}_{\mathrm{n}}$, which are usually defined to be dimensionless with mean zero and the same standard deviation. In terms of the coded variables the response function will be written as $f\left(\mathrm{x}_{1}, \mathrm{x}_{2}, \ldots, \mathrm{x}_{\mathrm{n}}\right)$;is called response surface. In most of the RSM problems the form of relationship between the response and the independent variable is unknown. Thus the first step in RSM is to find a suitable approximation for the true functional relationship between $\mathrm{Y}$ and set of independent variables employed. Usually a second order model is utilized in RSM.

$$
Y=\beta_{0}+\sum_{j=1}^{k} \beta_{j} X_{j}+\sum_{j=1}^{k} \beta_{j j} X_{j}^{2}+\sum_{i<} \sum_{j=2}^{k} \beta_{j j} X_{i} X_{j}
$$

The $\beta$ coefficients, used in the above model can be calculated by means of using least squares technique. The second order model is normally used when the response function is not known or nonlinear.

\subsection{Optimization by Genetic Algorithm}

Genetic algorithms (GA) are computerized search and optimization algorithms based on the mechanics of natural selection and natural genetics (Goldberg, 1989; Deb Kalyanmony, 1991) GA simulates the biological evolutionary process: Darwin's theory of survival of the fittest. The solution of the optimization problem with GA begins with a set of potential solutions or chromosomes that are randomly generated and selected the entire set of chromosomes comprises a population. The chromosomes evolve during several iterations or generations. New generations are generated using a crossover and mutation technique. Crossover involves splitting two chromosomes and then combining one half of each chromosome with other pair. Mutation involves flipping a single bit of a chromosome. The chromosomes are then evaluated using a certain fitness criteria and the best ones are kept while the others are discarded. This process is repeated until one chromosome has the best fitness and thus is taken as the best solution to the problem.

\section{Experimental details}

A detailed survey has been carried out to find out how the machining parameters affect surface rourhness of P20 mould. Based on this, the five machining parameters are nose radius, cutting speed, feed rate, axial depth of cut and radial depth of cut were selected. Taguchi's $\mathrm{L}_{50}\left(2^{1 * 5^{11}}\right)$ orthogonal array in the design of experiments (DOE) technique has been implemented to conduct the experiments. Nose radius with two levels and cutting speed, cutting feed, axial depth of cut and radial depth of cut with five levels each and then $2 \times 5 \times 5 \times 5 \times 5=1250$ runs were required in the experiments for five independent variables. But using Taguchi's orthogonal array, the number of experiments reduced to 50 experiments from 1250 experiments. All the experiments were conducted on CNC Vertical milling machine 600 II. The specifications of the Vertical milling machine are: The tool holder used for milling operation was KENAMETAL tool holder BT40ER40080M, Table clamping area: 20 TOOLS ATC STANDARD, Maximum load on the table: $700 \mathrm{kgs}$, Spindle taper: BT-40, Spindle speeds range: 8-8000rpm, Power: $13 \mathrm{~kW}$, Feed rates range: 0$12 \mathrm{~m} / \mathrm{min}$ and the too material used for the present study was coated carbide cutting tool. The coated carbide cutting tool has been found to perform better than uncoated carbide tools. Thus, commercially available CVD coated carbide tool inserts (TN 450) have been used in this investigation is shown in Figure 1. The machining parameters used and their levels chosen are presented in Table 2 .
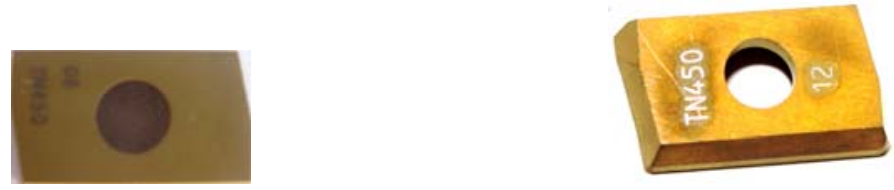

Figure 1. Tool inserts of nose radius $0.8 \mathrm{~mm}$ and $1.2 \mathrm{~mm}$

Table 2: Machining Parameters used and their Levels

\begin{tabular}{|l|l|l|l|l|l|l|l|}
\hline \multirow{2}{*}{ Control parameters } & \multirow{2}{*}{ Units } & \multirow{2}{*}{ symbol } & \multicolumn{5}{|c|}{ Levels } \\
\cline { 4 - 9 } & & & Level 1 & Level 2 & Level 3 & Level 4 & Level 5 \\
\hline Nose radius & $\mathrm{mm}$ & $\mathrm{R}$ & 0.8 & 1.2 & - & - & - \\
\hline Cutting speed & $\mathrm{m} / \mathrm{min}$ & $\mathrm{v}$ & 75 & 80 & 85 & 90 & 95 \\
\hline Feed & $\mathrm{mm} /$ tooth & $\mathrm{f}$ & 0.1 & 0.125 & 0.15 & 0.175 & 0.2 \\
\hline Axial depth of cut & $\mathrm{mm}$ & $\mathrm{d}$ & 0.5 & 0.75 & 1 & 1.25 & 1.5 \\
\hline Radial depth of cut & $\mathrm{mm}$ & $\mathrm{rd}$ & 0. & 0.4 & 0.5 & 0.6 & 0.7 \\
\hline
\end{tabular}


The average surface roughness $\left(\mathrm{R}_{\mathrm{a}} \mu \mathrm{m}\right)$ which is mostly used in industrial environments is taken up for the present study. The average surface roughness is the integral absolute value of the height of the roughness profile over the evaluation length and was represented by the Eq. (4).

$\mathrm{R}_{\mathrm{a}}=1 / \int_{0}^{\mathrm{L}}|\mathrm{Y}(\mathrm{x}) \mathrm{dx}|$

Where $\mathrm{L}$ is the length taken for observation and $\mathrm{Y}$ is the ordinate of the profile curve. The surface roughness was measured three times for each of the 50 cases tested by using Surtronic $3^{+}$stylus type instrument manufactured by Taylor Hobson with the following specifications. Traverse Speed: $1 \mathrm{~mm} / \mathrm{sec}$, Cut-off values $0.25 \mathrm{~mm}, 0.80 \mathrm{~mm}$ and $2.50 \mathrm{~mm}$, Display LCD matrix, Battery Alcaline 600 measurements of $4 \mathrm{~mm}$ measurement length and averaged. The experimental layout (Montgomery, 1984) is presented in Table 3 and results are shown in Figure 2.

Table 3. $\mathrm{L}_{50}\left(2^{1 * 5^{11}}\right)$ orthogonal array

\begin{tabular}{cccccccccccc}
\hline S. NO & R & V & f & d & rd & S. NO & R & V & f & d & rd \\
\hline 1 & 1 & 1 & 1 & 1 & 1 & 26 & 2 & 1 & 1 & 1 & 4 \\
2 & 1 & 1 & 2 & 2 & 2 & 27 & 2 & 1 & 2 & 2 & 5 \\
3 & 1 & 1 & 3 & 3 & 3 & 28 & 2 & 1 & 3 & 3 & 1 \\
4 & 1 & 1 & 4 & 4 & 4 & 29 & 2 & 1 & 4 & 4 & 2 \\
5 & 1 & 1 & 5 & 5 & 5 & 30 & 2 & 1 & 5 & 5 & 3 \\
6 & 1 & 2 & 1 & 2 & 3 & 31 & 2 & 2 & 1 & 2 & 1 \\
7 & 1 & 2 & 2 & 3 & 4 & 32 & 2 & 2 & 2 & 3 & 2 \\
8 & 1 & 2 & 3 & 4 & 5 & 33 & 2 & 2 & 3 & 4 & 3 \\
9 & 1 & 2 & 4 & 5 & 1 & 34 & 2 & 2 & 4 & 5 & 4 \\
10 & 1 & 2 & 5 & 1 & 2 & 35 & 2 & 2 & 5 & 1 & 5 \\
11 & 1 & 3 & 1 & 3 & 5 & 36 & 2 & 3 & 1 & 3 & 3 \\
12 & 1 & 3 & 2 & 4 & 1 & 37 & 2 & 3 & 2 & 4 & 4 \\
13 & 1 & 3 & 3 & 5 & 2 & 38 & 2 & 3 & 3 & 5 & 5 \\
14 & 1 & 3 & 4 & 1 & 3 & 39 & 2 & 3 & 4 & 1 & 1 \\
15 & 1 & 3 & 5 & 2 & 4 & 40 & 2 & 3 & 5 & 2 & 2 \\
16 & 1 & 4 & 1 & 4 & 2 & 41 & 2 & 4 & 1 & 4 & 5 \\
17 & 1 & 4 & 2 & 5 & 3 & 42 & 2 & 4 & 2 & 5 & 1 \\
18 & 1 & 4 & 3 & 1 & 4 & 43 & 2 & 4 & 3 & 1 & 2 \\
19 & 1 & 4 & 4 & 2 & 5 & 44 & 2 & 4 & 4 & 2 & 3 \\
20 & 1 & 4 & 5 & 3 & 1 & 45 & 2 & 4 & 5 & 3 & 4 \\
21 & 1 & 5 & 1 & 5 & 4 & 46 & 2 & 5 & 1 & 5 & 2 \\
22 & 1 & 5 & 2 & 1 & 5 & 47 & 2 & 5 & 2 & 1 & 3 \\
23 & 1 & 5 & 3 & 2 & 1 & 48 & 2 & 5 & 3 & 2 & 4 \\
24 & 1 & 5 & 4 & 3 & 2 & 49 & 2 & 5 & 4 & 3 & 5 \\
25 & 1 & 5 & 5 & 4 & 3 & 50 & 2 & 5 & 5 & 4 & 1 \\
\hline
\end{tabular}

\section{Results and discussion}

In order to satisfy the present day's needs of manufacturing industry, carbide inserts with the above specifications were identified. The $\mathrm{L}_{50}$ orthogonal array was adopted for the present investigation. So 50 experiments were conducted and the average surface roughness of all these components was measured and was used to build mathematical model using RSM. The second order response surface representing the surface roughness can be expressed as function of cutting parameters such as nose radius (mm), cutting speed $(\mathrm{m} / \mathrm{min})$, feed $(\mathrm{mm} / \mathrm{tooth})$, axial depth of cut $(\mathrm{mm})$ and radial depth of cut $(\mathrm{mm})$. The relationship between the surface roughness and machining parameters has been expressed as follows

$R_{a}=\beta_{0}+\beta_{1}(\mathrm{R})+\beta_{2}(\mathrm{~V})+\beta_{3}(\mathrm{f})+\beta_{4}(\mathrm{~d})+\beta_{5}(\mathrm{rd})+\beta_{6} \mathrm{R}^{2}+\beta_{7} \mathrm{v}^{2}+\beta_{8} \mathrm{f}^{2}+\beta_{9} \mathrm{~d}^{2}+\beta_{10} \mathrm{rd}^{2}+\beta_{11} \mathrm{R} \times \mathrm{v}+\beta_{12} \mathrm{R} \times \mathrm{f}+\beta_{13} \mathrm{R} \times \mathrm{d}+\beta_{14} \mathrm{R} \times \mathrm{rd}+\beta_{15} \mathrm{~V} \times \mathrm{f}$ $+\beta_{16} \mathrm{~V} \times \mathrm{d}+\beta_{17} \mathrm{~V} \times \mathrm{rd}+\beta_{18} \mathrm{~d} \times \mathrm{rd}$

From the observed data for surface roughness, the estimated regression coefficients for average surface roughness in un-coded units have been determined using least square technique.

The multiple regression coefficient of the second order model was found to be 0.506 . This shows that second order model can explain the variation of the extent of $50.6 \%$. The adjusted $\mathrm{R}^{2}$ is $38.0 \%$. The estimated regression coefficients are presented in Table 4.

The response function has been determined in un-coded units as 
$R_{a}=-23.8203-2.26500 * R+0.517555^{*} \mathrm{~V}+111.261 * f-7.06930 * d-0.00291143 * V^{\wedge} 2-138.248 * f^{\wedge} 2-1.07124 * d^{\wedge} 2+20.4200 * R^{*} f-$ $0.963810 * \mathrm{~V} * \mathrm{f}+0.0988190 * \mathrm{~V} * \mathrm{~d}$

Results of ANOVA for the response function surface roughness are presented in the Table 5. This analysis is carried out for a level of significance of $5 \%$ i.e., for a level of confidence of $95 \%$.

Table 4: Estimated regression coefficients

\begin{tabular}{llccc}
\hline Term & Coef & SE Coef & $\mathrm{T}$ & $\mathrm{P}(<0.05)$ \\
\hline Constant & 1.4839 & 0.18973 & 7.821 & 0.000 \\
$\mathrm{R}$ & 0.1596 & 0.07322 & 2.180 & $<0.035$ \\
$\mathrm{~V}$ & -0.2314 & 0.10355 & -2.235 & $<0.031$ \\
$\mathrm{f}$ & 0.4141 & 0.11522 & 3.594 & $<0.001$ \\
$\mathrm{~d}$ & -0.4061 & 0.11522 & -3.524 & $<0.001$ \\
$\mathrm{~V} * \mathrm{~V}$ & -0.2911 & 0.17503 & -1.663 & $<0.004$ \\
$\mathrm{~F}^{*} \mathrm{~F}$ & -0.3456 & 0.20211 & -1.710 & $<0.045$ \\
$\mathrm{~d}^{*} \mathrm{~d}$ & -0.2678 & 0.20211 & -1.325 & $<0.019$ \\
$\mathrm{R}$ & 0.2042 & 0.10355 & 1.972 & $<0.046$ \\
$\mathrm{~V} * \mathrm{~F}$ & -0.4819 & 0.20211 & -2.384 & $<0.022$ \\
$\mathrm{~V} * \mathrm{~d}$ & 0.4941 & 0.20211 & 2.445 & $<0.019$ \\
\hline
\end{tabular}

Table 5. Analysis of variance of $R_{a}$

\begin{tabular}{lcccccc}
\hline Source & DF & Seq SS & Adj SS & AdjMS & F & P \\
\hline Regression & 10 & 10.7228 & 10.7228 & 1.07228 & 4.00 & 0.001 \\
Linear & 4 & 6.7627 & 8.8092 & 2.20229 & 8.22 & 0.000 \\
Square & 3 & 0.8330 & 1.8619 & 0.62064 & 2.32 & 0.049 \\
Interaction & 3 & 3.1272 & 3.1272 & 1.04239 & 3.89 & 0.016 \\
Residual Error 39 & 10.4546 & 10.4546 & 0.26807 & & \\
\hline Total & 49 & 21.1775 & & &
\end{tabular}

From the analysis of Table 5, it is apparent that, the $\mathrm{F}$ calculated value is greater than $\mathrm{F}$ table value $\left(\mathrm{F}_{0.05}, 10,39=2.088\right)$. Hence the second order response function developed is adequate. Figure 2 shows the comparison of experimental values with RSM predicted results.

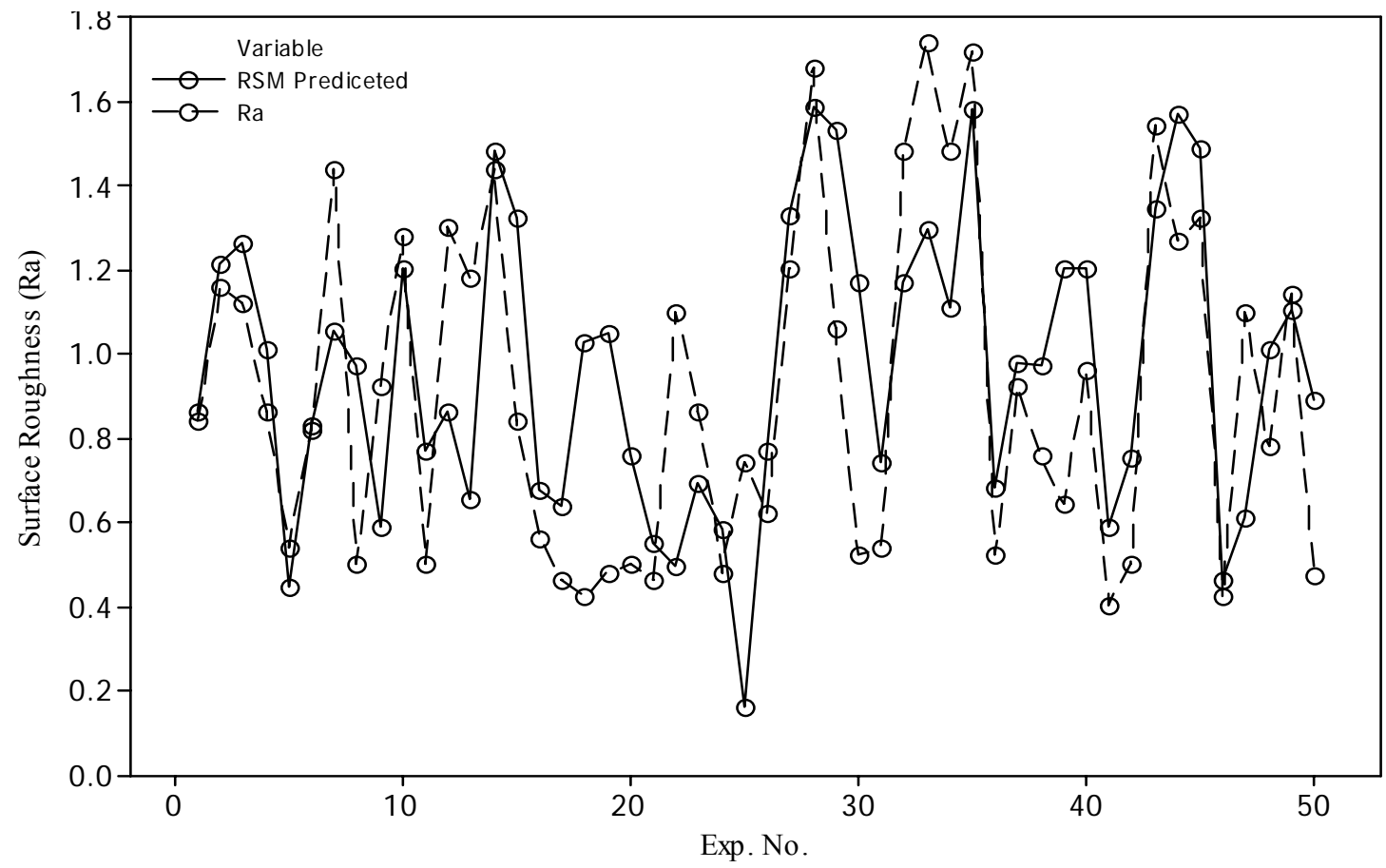

Figure 2. Surface roughness vs. Experiment number for train data 


\subsection{Validation of experimental results}

To predict and verify the improvement in the surface roughness for machining of P20 mould steel by milling process with respect to the chosen initial parameters setting, verification test are used. The validity of the response surface model was checked by the test data presented in Table 6 and is shown in Figure 3. From the analysis of Figure 3, it can be observed that the predicted values are very close to the experimental results.

Table 6. Test data and predicted results

\begin{tabular}{|r|c|c|c|c|c|l|l|}
\hline S.No. & $\mathrm{R}$ & $\mathrm{V}$ & $\mathrm{f}$ & $\mathrm{d}$ & $\mathrm{rd}$ & Exp. Ra & Predicted Ra by RSM \\
\hline 1. & 0.8 & 87 & 0.14 & 1.35 & 0.6 & 0.78 & 0.88352 \\
\hline 2. & 0.8 & 87 & 0.16 & 1.35 & 0.4 & 1.02 & 0.92894 \\
\hline 3. & 1.2 & 78 & 0.16 & 1.35 & 0.4 & 1.16 & 1.18253 \\
\hline 4. & 1.2 & 78 & 0.16 & 0.8 & 0.6 & 1.56 & 1.59804 \\
\hline 5. & 1.2 & 87 & 0.16 & 0.8 & 0.4 & 1.24 & 1.75618 \\
\hline 6. & 1.2 & 87 & 0.14 & 1.35 & 0.4 & 0.94 & 1.12104 \\
\hline 7. & 1.2 & 87 & 0.14 & 0.8 & 0.6 & 1.18 & 1.54740 \\
\hline
\end{tabular}

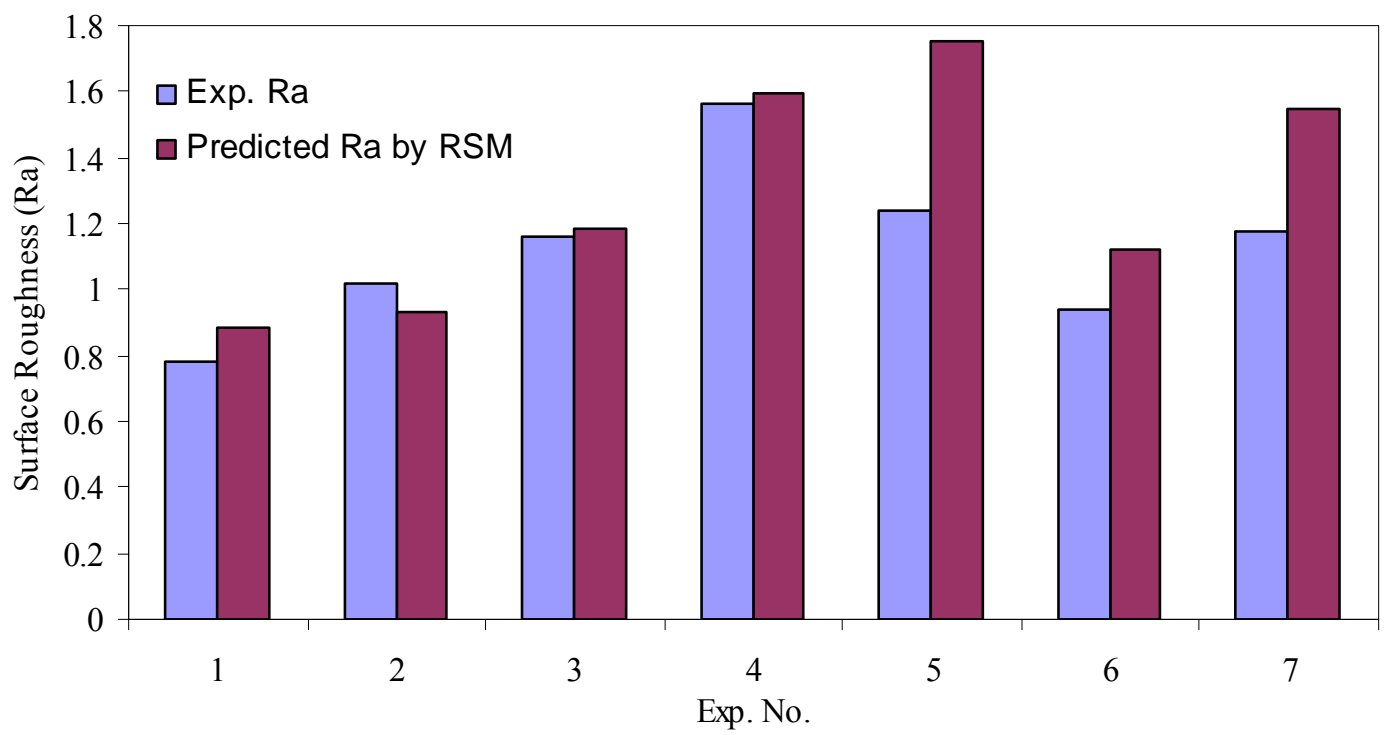

Figure 3. Surface roughness vs. Experiment number for test data

\subsection{Surface Roughness Optimization with Genetic Algorithm}

The minimum surface roughness within the ranges of process parameters to be determined using a global optimization method: genetic algorithm (GA). The surface roughness optimization problem for the P20 mould steel can be defined in the standard mathematical format as below

Find: surface roughness

To minimize: surface roughness $(\mathrm{R}, \mathrm{v}, \mathrm{f}, \mathrm{d}, \mathrm{rd})$

Within parameter ranges:

$0.8 \mathrm{~mm} \leq \mathrm{R} \leq 1.2 \mathrm{~mm}$

$75 \mathrm{~m} / \mathrm{min} \leq \mathrm{V} \leq 95 \mathrm{~m} / \mathrm{min}$

$0.1 \mathrm{~mm} /$ tooth $\leq \mathrm{f} \leq 0.2 \mathrm{~mm} /$ tooth

$0.5 \mathrm{~mm} \leq \mathrm{d} \leq 1.5 \mathrm{~mm}$

$0.3 \mathrm{~mm} \leq \mathrm{rd} \leq 0.7 \mathrm{~mm}$

To solve the above optimization problem efficiently, an effective GA has been written in MATLAB programming language. The developed GA is coupled with the RS model for surface roughness to yield a global optimum. The critical parameters in GAs are the size of population, cross over probability, mutation rate, number of generations (i.e., iterations), etc.

In this study population size of 40 , crossover rate of 0.9 , mutation rate is of constraint dependent and the number of generations of 50 and constrained solver FMINCON as hybrid function are employed.

The developed GA in this study, stochastic uniform selection has been used to select the chromosomes. Fitness values of the chromosomes are biased towards the minimum objective value and the least infeasible sets in crossover phase.

GA reduces the surface roughness of the P20 mould steel from $0.5 \mu \mathrm{m}$ to $0.2789 \mu \mathrm{m}$ by about $44.22 \%$ after optimization. Surface roughness corresponding to the optimum process parameters and initial process parameters are compared in Table 6 . 
Table 6: Surface roughness parameters before and after optimization

\begin{tabular}{|l|l|l|l|l|l|l|}
\hline & $\mathrm{R} \mathrm{mm}$ & $\mathrm{V} \mathrm{m} / \mathrm{min}$ & $\mathrm{f} \mathrm{mm} /$ tooth & $\mathrm{d} \mathrm{mm}$ & $\mathrm{rd} \mathrm{mm}$ & $\mathrm{Ra} \mu \mathrm{m}$ \\
\hline Before optimization & 1.2 & 90 & 0.125 & 1.5 & 0.3 & 0.5 \\
\hline After optimization & 0.8 & 95 & 0.1 & 1.5 & 0.7 & 0.2789 \\
\hline
\end{tabular}

The surface roughness of P20 mould steel with optimization history in iterations is demonstrated in Figure 4. From Table 6, it is seen that the optimum surface roughness value $(0.2789)$ predicted from GA correlates very well to that of $(0.2867)$ from experiments.

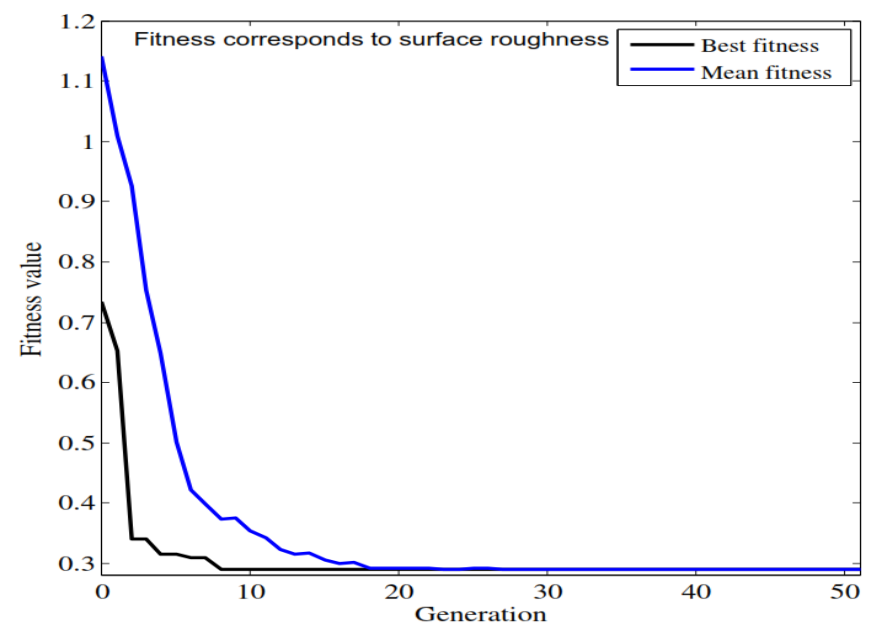

\section{Conclusions}

Figure 4. Optimization history with iterations for surface roughness

In this study, an efficient optimization methodology using RSM and GA is introduced in minimizing surface roughness of P20 mould steel in $\mathrm{CNC}$ end milling process. To achieve the minimum surface roughness, the appropriate process parameters are determined. Nose radius, cutting speed, feed rate, axial depth of cut and radial depth of cut are considered as process parameters. A predictive model for surface roughness is created in terms of the process parameters using RSM to increase the quality of the surface finish. The RSM model is interfaced with an effective GA to find the optimum process parameter values. GA has reduced the surface roughness of the initial model significantly. Surface roughness is improved by about $44.22 \%$.

\section{References}

Abbas Fadhel Ibraheem, Saad Kareem Shather, and Kasim A. Khalaf. 2008. Prediction of Cutting Forces by using Machine Parameters in end Milling Process. J. Eng. \& Tech. Vol.26, No. 11, pp. 1-4.

Abou-El-Hossein, K.A., Kadirgama, K., Hamdi, M., Benyounis, K.Y. 2007. Prediction of cutting force in end-milling operation of modified AISI P20 tool steel. J Mater Process Technol. Vol.182, No.1-3, pp. 241-247.

Bala Murugan Gopalswamy et al. 2009. Taguchi method and ANOVA: An approach for process parameters of optimization of hard machining while machining hardened steel. Vol. 68, pp. 686-695.

Deb kalyanmony., 1995. Optimization for engineering design- algorithms and examples. Prentice-Hall, India.

Ekanayake, R.A. and Mathew. P. 2007. An Experimental Investigation of High Speed End Milling. Proc. of $5^{\text {th }}$ Australasian Congress on Applied Mechanics, ACAM 2007 10-12 December, Brisbane, Australia, pp. 1-7.

Goldberg, D.E., 1989. Genetic algorithms in search, optimization and machine learning in. Addision-wesley.

Helen Coldwell, Richard Woods, Martin Paul, Philip Koshy, Richard Dewes, David Aspinwall. 2003. Rapid machining of hardened AISI H13 and D2 moulds dies and press tools. J. Mat. Proc. Tech. Vol.135, pp. 301-311.

John L., Yang, and Joseph C. Chen. 2001. A systematic approach for identifying optimum surface roughness performance in end milling operations. Journal of industrial technology, Vol.17, No. 2, pp. 1-8.

Kadirgama et al. 2008. Optimization of Surface Roughness in End Milling on Mould Aluminum Alloys (AA6061-T6) Using Response Surface Method and Radian Basis Function Network. Jordan Journal of Mechanical and Industrial Engineering Vol.2, November 4, pp. 209- 214.

Kadirgama et al. 2010. Response Ant Colony Optimization of End Milling Surface Roughness Sensors 2010. Vol.10, 2054-2063; doi: $10.3390 / \mathrm{s} 100302054$.

Lajis. M.A., Mustafizul KARIM. A.N., Nurul AMIN. A.K.M., HAFIZ. A.M.K. and Turnad. L.G., 2008. Prediction of Tool Life in End Milling of Hardened Steel AISI D2. European Journal of Scientific Research, Vol.21, No. 4, pp. 592-602.

Liao. Y.S., and Lin. H.M., 2007. Mechanism of minimum quantity lubrication in high-speed milling of hardened steel. Int. J. 
Machine Tools and Manuf., Vol.47, No. 11, pp. 1660-1666.

Mike S. Lou., Joseph C. Chen., and Caleb M. Li.,1999. Surface roughness prediction technique for CNC end milling. Journal of Industrial Technology, Vol.17, No. 2-7, pp. 2-6

Mohammad Reza Soleymani Yazdi and Saeed Zare Chavoshi. 2010. Analysis and estimation of state variables in CNC face milling of AL6061., Prod. Eng. Res. Devel. Vol.4, pp. 535-543, doi: 10.1007/s11740-010-0232-7.

Montgomery. D.C.,1991. Design and analysis of experiment. John Willey and Sons, New York,

Muammer Nalbant, Hasan Gokkaya, and Ihsan Toktas,2007. Comparison of Regression and Artificial Neural Network Models for Surface Roughness Prediction with the Cutting Parameters in CNC Turning. Modelling and Simulation in Engineering. pp. 114, doi:10.1155/2007/92717.

Oktem. H., Erzurumlu. T., Kurtaran. H., 2005. Application of response surface methodology in the optimization of cutting conditions for surface roughness. J. Mater. Process. Technol. Vol.170, pp. 11-16.

Rahman. M., Senthil Kumar. A., and Salem Manzoor, U.I., 2001. Evaluation of minimal quantities of lubricant in end milling. Int. J. Advanced Manuf. Tech, Vol.18, No. 4, pp.235-241.

Rahman. M., Senthil Kumar. A., and Salam. M.U., 2002. Experimental evaluation of the effect of minimal quantities of lubricant in milling. Int. J. Machine Tools and Manuf. Vol.42, No. 5, pp.539-547.

Saurav Datta et al.,2010. Optimization of CNC end milling process parameters using PCA-based Taguchi method. International Journal of Engineering, Science and Technology, Vol. 2, No. 1, pp. 92-102.

Suresh. P.V.S., Rao. P.V., Deshmukh. S.G.,2002. A genetic algorithmic approach for optimization of surface roughness prediction model. Int. J. Mach. Tools and Manuf., Vol.42, pp. 675-680.

\section{Biographical notes}

Mr.B.Sidda Reddy, obtained his Masters Degree from S.V University, Tirupati in 2007.He is working as Assistant Professor in the Department of Mechanical Engineering in R.G.M College of Engg. \& Tech.Nandyal, Andhra Pradesh Since 2005.He has presented 09 papers in National and International Conferences, 07 papers has published in National Journal and 15 papers has published in International Journal. His areas of interests are I.C Engines, Alternative fuels \& CFD, Optimization techniques, soft computing, Composite materials.

Dr. J. Suresh Kumar is currently working as Associate Professor in Mechanical Engineering in Jawaharlal Nehru Technological University, Hyderabad. He completed his Masters in 1995 and did his Ph.D from JNTU College of Engineering, Kakinada in 2005. He has presented / Published 25 papers in Various National \& International Conferences / Journals. He has organized 3 National level conferences \& short term courses. He is a life member of I.S.T.E. He worked as Erection and Plant engineer at Golden Agro- Tech Industries Ltd during 1992-1996. His areas of interests are Alternative fuels \& CFD, Optimization techniques, soft computing and Composite structures.

Dr. K. Vijaya Kumar Reddy, is graduated in 1988, Masters in 1992 and did his Ph.D from JNTU College of Engg., Anantapur in 2000. He guided three Ph.D students and another $16 \mathrm{Ph}$. D scholars doing their research under his guidance. He has presented and published more than 100 papers in Various National \& International Conferences. He has organized 7 national level conferences \& short term courses and attended 6 National workshops during past 6 years. He had supervised the following important activities at JNTUCE, Anantapur such as NSS Programme officer, Deputy Warden, Officer in charge of hostels, Student Union coordinator, Alumni Association Secretary cum Treasurer, Officer in charge of Academic section. At Present, he is working as Professor of Mechanical Engineering at Jawaharlal Nehru Technological University, Hyderabad

Received November 2011

Accepted March 2012

Final acceptance in revised form March 2012 